\title{
Exercise Metabolism: Fuels for the Fire
}

\author{
Mark Hargreaves ${ }^{1}$ and Lawrence L. Spriet ${ }^{2}$ \\ ${ }^{1}$ Department of Physiology, The University of Melbourne, Victoria 3010, Australia \\ ${ }^{2}$ Department of Human Health and Nutritional Sciences, University of Guelph, Guelph, Ontario \\ N1G 2W1, Canada \\ Correspondence: m.hargreaves@unimelb.edu.au
}

\begin{abstract}
During exercise, the supply of adenosine triphosphate (ATP) is essential for the energydependent processes that underpin ongoing contractile activity. These pathways involve both substrate-level phosphorylation, without any need for oxygen, and oxidative phosphorylation that is critically dependent on oxygen delivery to contracting skeletal muscle by the respiratory and cardiovascular systems and on the supply of reducing equivalents from the degradation of carbohydrate, fat, and, to a limited extent, protein fuel stores. The relative contribution of these pathways is primarily determined by exercise intensity, but also modulated by training status, preceding diet, age, gender, and environmental conditions. Optimal substrate availability and utilization before, during, and after exercise is critical for maintaining exercise performance. This review provides a brief overview of exercise metabolism, with expanded discussion of the regulation of muscle glucose uptake and fatty acid uptake and oxidation.
\end{abstract}

$T_{\mathrm{in}}^{\mathrm{h}}$ he maintenance of contractile activity during exercise is critically dependent on the supply of adenosine triphosphate (ATP) to the myosin, $\mathrm{Na}^{+}-\mathrm{K}^{+}$, and sarcoplasmic reticulum $\mathrm{Ca}^{2+}$ ATPases that are essential for myofilament force production and the maintenance of sarcolemmal excitability and sarcoplasmic reticulum $\mathrm{Ca}^{2+}$ reuptake and release during excitationcontraction coupling. Because the intramuscular stores of ATP are small $\left(\sim 5 \mathrm{mmol} \cdot \mathrm{kg}^{-1}\right.$ wet muscle), sole reliance on them would only sustain exercise for short periods. For example, during submaximal exercise at a power output (200 $\mathrm{W})$ requiring $\sim 75 \%$ maximal oxygen uptake $\left(\mathrm{VO}_{2 \max }\right)$, with an estimated ATP utilization rate of $0.4 \mathrm{mmol}$ ATP $\cdot \mathrm{kg}^{-1} \mathrm{sec}^{-1}$, exercise duration would be $15 \mathrm{sec}$. During "all-out," maximal exercise at a power output $(\sim 900 \mathrm{~W})$ re- quiring $\sim 300 \% \mathrm{VO}_{2 \max }$, the values would be $3.7 \mathrm{mmol}$ ATP. $\mathrm{kg}^{-1} \mathrm{sec}^{-1}$ and $<2 \mathrm{sec}$, respectively. Thus, other metabolic pathways must be activated to resynthesize ATP for the energydependent processes in contracting skeletal muscle. These pathways (Table 1) involve both substrate-level phosphorylation, without any need for oxygen, and oxidative phosphorylation that is critically dependent on oxygen delivery to contracting skeletal muscle by the respiratory and cardiovascular systems and on the supply of reducing equivalents from the degradation of fuel stores (Hawley et al. 2014). Although amino acids can be oxidized by contracting skeletal muscle, they make a relatively minor contribution to exercise metabolism, with carbohydrates and fat being the primary substrates for oxidative metabolism during exercise (Ro-

Editors: Juleen R. Zierath, Michael J. Joyner, and John A. Hawley

Additional Perspectives on The Biology of Exercise available at www.perspectivesinmedicine.org

Copyright (C) 2018 Cold Spring Harbor Laboratory Press; all rights reserved; doi: 10.1101/cshperspect.a029744

Cite this article as Cold Spring Harb Perspect Med 2018;8:a029744 
M. Hargreaves and L.L. Spriet

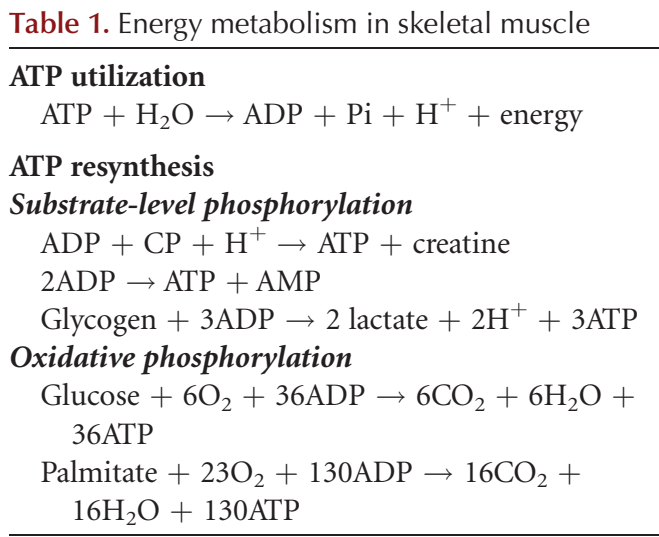

ATP, Adenosine triphosphate; ADP, adenosine diphosphate.

mijn et al. 1993; van Loon et al. 2001). The metabolic responses to exercise have been well studied and described since the early 20th century. This review provides a brief overview of exercise metabolism and more in-depth summaries of skeletal muscle glucose uptake and glucose transporter type 4 (GLUT4) translocation and skeletal muscle fatty acid (FA) oxidation during exercise.

\section{OVERVIEW OF EXERCISE METABOLISM}

The major determinants of the relative contribution of the energy-generating pathways (Fig. 1; Table 1) during exercise are the intensity and duration of exercise. During maximal, "allout" exercise, with a peak power output of $\sim 900 \mathrm{~W}$, which declines over the next $30 \mathrm{sec}$, the degradation of creatine phosphate and of glycogen to lactate provide the majority of ATP, while oxidative phosphorylation accounts for $\sim 25 \%-30 \%$ of energy turnover (Fig. 2). The rapid increase in muscle glycogenolysis is the result of activation of glycogen phosphorylase by increased sarcoplasmic $\left[\mathrm{Ca}^{2+}\right]$ and inorganic phosphate $(\mathrm{Pi})$, elevated cyclic AMP secondary to increased circulating adrenaline, and allosteric activation by ATP breakdown products (AMP, ADP, and IMP). The increase in $\mathrm{Ca}^{2+}$, along with elevated muscle pyruvate levels caused by increased glycolysis, activates pyruvate dehydrogenase $(\mathrm{PDH})$, the rate-limiting enzyme for muscle carbohydrate oxidation
(Parolin et al. 1999). Despite the increased PDH activity, the rate of pyruvate production from glycolysis is higher than PDH activity, resulting in significant generation of lactate that accumulates in both the muscle and blood. The marked increases in ATP utilization, glycolysis, and strong ion fluxes during such exercise result in metabolic acidosis.

The decline in power output (fatigue) during single and repeated bouts of maximal exercise is associated with creatine phosphate and glycogen depletion (Spriet et al. 1989; Casey et al. 1996; Hargreaves et al. 1998), accumulation of metabolic by-products (e.g., $\mathrm{H}^{+}$, ADP, AMP, Pi) (Spriet et al. 1989; Casey et al. 1996; Hargreaves et al. 1998), and hyperkalemia (Medbø and Sejersted 1990), which singly and in combination impact on excitation-contraction coupling processes within skeletal muscle (Allen et al. 2008).

During submaximal exercise, the oxidative metabolism of carbohydrates and lipids provides almost all of the ATP required for contractile activity. The major substrates for oxidation are muscle glycogen and blood glucose derived from liver glycogenolysis and gluconeogenesis and the gut when carbohydrate is ingested, and FAs derived from both adipose tissue and intramuscular triglyceride (IMTG) breakdown. The relative contribution of these substrates is largely determined by exercise intensity (Fig. 3) (Romijn et al. 1993; van Loon et al. 2001) and duration, but is also influenced by training status, gender, preceding diet, and environmental conditions, although these latter factors are beyond the scope of the current review. At lower intensities lipid oxidation dominates, but with increasing exercise intensity there is greater reliance on muscle glycogen and blood glucose. Maximal rates of fat oxidation, from both extraand intramuscular FAs, occur at $\sim 60 \%-65 \%$ $\mathrm{VO}_{2 \max }$, declining at higher intensities as a result of reduced plasma FA delivery to contracting skeletal muscle and lower rates of mitochondrial FA uptake and oxidation, secondary to increased glycolytic flux (Romijn et al. 1995; Spriet 2014). Increased muscle glycogenolysis at higher exercise intensities is the result of enhanced glycogen phosphorylase activity, secondary to elevated 


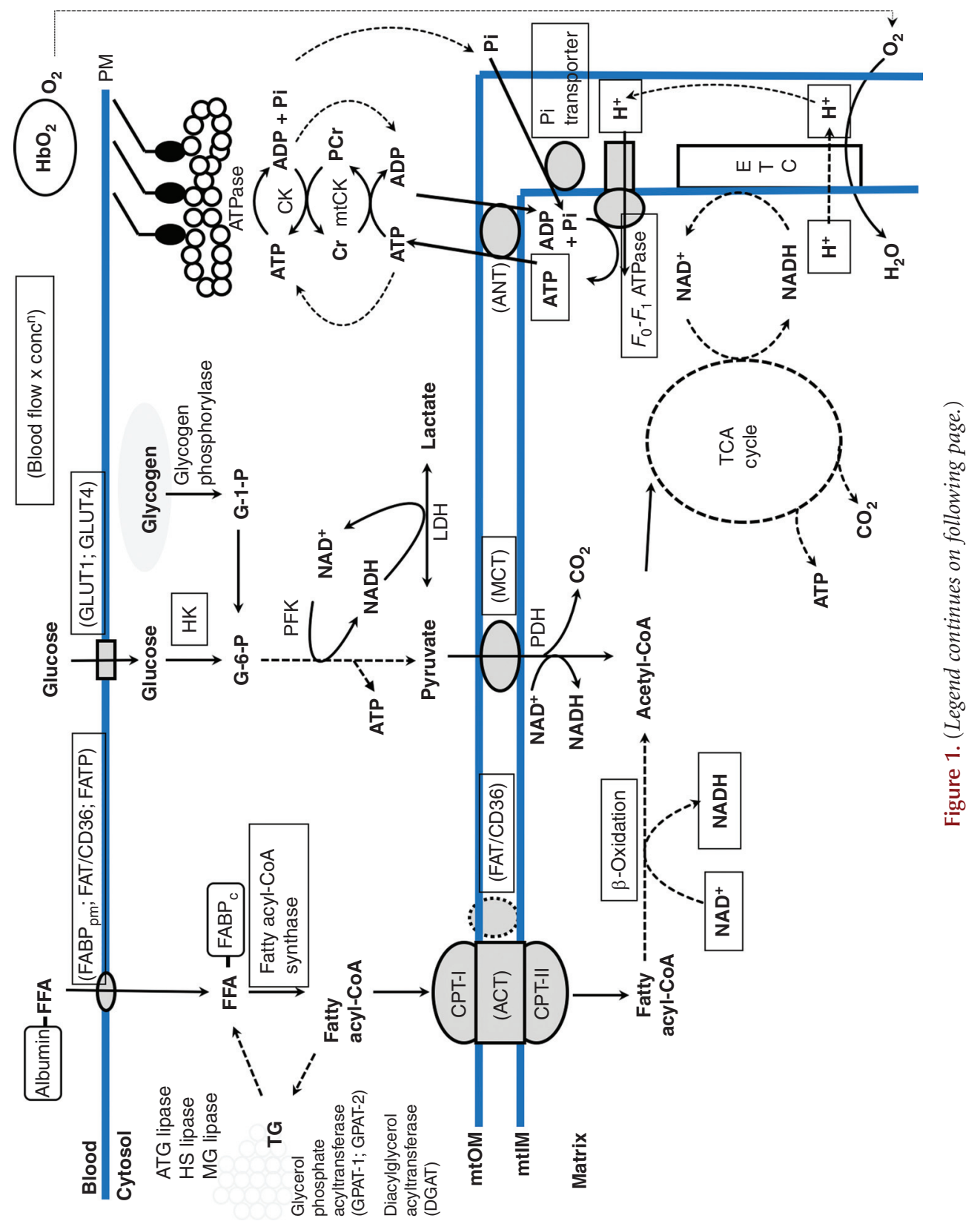




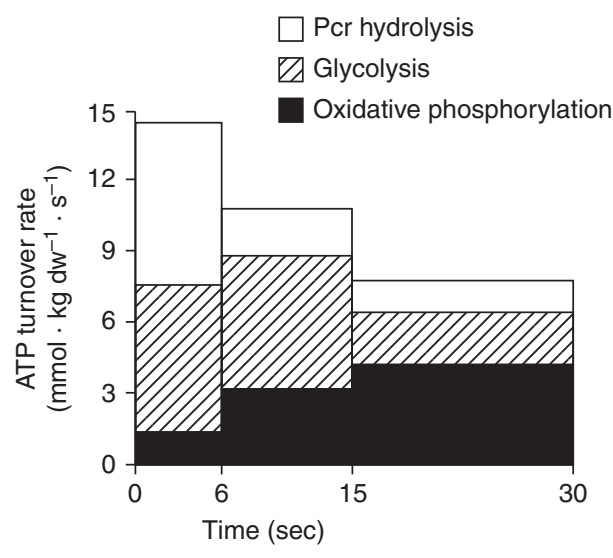

Figure 2. Contributions of phosphocreatine (PCr), glycolysis, and oxidative phosphorylation to adenosine triphosphate (ATP) turnover during $30 \mathrm{sec}$ of maximal isokinetic cycling exercise. (From Parolin et al. 1999; reprinted, with permission, from the authors.)

sarcoplasmic $\mathrm{Ca}^{2+}, \mathrm{Pi}$, and cyclic AMP following adrenaline stimulation and allosteric activation by ATP breakdown products (Howlett et al. 1998; Watt et al. 2001). Glucose uptake also increases in relation to exercise intensity, although glucose utilization may decrease during intense exercise because of high rates of muscle glycogenolysis and glucose-6-phosphate-mediated inhibition of hexokinase activity (Katz et al. 1986). Accompanying the increase in skeletal muscle glucose uptake is enhanced liver glucose output, initially from liver glycogenolysis but during more prolonged exercise from increased rates of gluconeogenesis. Rates of carbohydrate oxidation are increased with increasing exercise intensity in parallel, with PDH activation (Howlett et al. 1998). Despite the increased PDH activity, accelerated rates of glycolysis also result in production of lactate that accumulates in muscle and blood (Spriet et al. 2000). Although lactate is often considered simply a metabolic by-product, it is an important substrate for oxidative metabolism and gluconeogenesis, thereby providing a link between glycolytic and oxidative metabolism (Brooks 2009).

During prolonged, strenuous $(\sim 75 \%$ $\mathrm{VO}_{2 \max }$ ) exercise, there is a progressive decline in the rate of muscle glycogenolysis and lipolysis, increased muscle glucose uptake, and a progressive increase in FA oxidation with elevated plasma FA levels (Romijn et al. 1993) with increasing exercise duration. Fatigue during such exercise is often associated with muscle and liver glycogen depletion and hypoglycemia, with a consequent decrease in muscle carbohydrate oxidation and neuroglucopenia. Increased dietary carbohydrate intake to maximize pre-exercise carbohydrate stores (Hawley et al. 1997) and carbohydrate ingestion during exercise (Cermak and van Loon 2013) are effective nutritional strategies to enhance endurance exercise performance.

\section{EXERCISE-INDUCED MUSCLE GLUCOSE UPTAKE AND GLUT4 TRANSLOCATION}

Although muscle glycogen is quantitatively more important as a carbohydrate fuel source for contracting skeletal muscle during exercise, blood glucose nevertheless makes an important contribution to overall carbohydrate oxidation, especially during prolonged, strenuous exercise. There has been considerable interest in the regulation of skeletal muscle glucose uptake during exercise, because it is preserved in states of insulin resistance such as type 2 dia-

Figure 1. (Continued) Schematic overview of skeletal muscle metabolism. Hb, Hemoglobin; FFA, free fatty acid; $\mathrm{FABP}_{\mathrm{pm}}$ and $\mathrm{FABP}_{\mathrm{c}}$, fatty acid binding protein-plasma membrane and cytoplasm; FAT/CD36, fatty acid translocase; FATP, fatty acid transport protein; GLUT1 and 4, glucose transport proteins 1 and 4; PM, plasma membrane; ATG, HS, and MG lipases, adipocyte glyceride, hormone-sensitive, and monoglyceride lipases; mtOM and mtIM, outer and inner mitochondrial membranes; CPT-I and -II, carnitine palmitoyl transferase I and II; ACT, acylcarnitine transferase; G-1-P and G-6-P, glucose 1 and 6 phosphate; HK, hexokinase; PFK, phosphofructokinase; $\mathrm{LDH}$, lactate dehydrogenase, $\mathrm{MCT}$, monocarboxylate transport proteins; $\mathrm{PDH}$, pyruvate dehydrogenase; TCA, tricarboxylic acid; ANT, adenine nucleotide transport protein; $\mathrm{Cr}$ and $\mathrm{PCr}$, creatine and phoshocreatine; $\mathrm{CK}$ and $\mathrm{mtCK}$, creatine kinase and mitochondrial CK. 


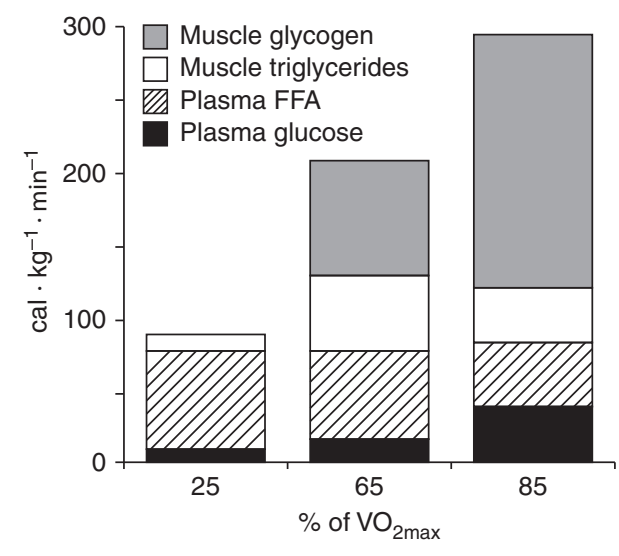

Figure 3. Relative contribution of carbohydrate and fat fuel sources to energy metabolism during exercise of increasing intensity. FFA, Free fatty acid. (From Romijn et al. 1993; reprinted, with permission, from the American Physiological Society (C) 1993.)

betes (Martin et al. 1995). It is well known that the effects of insulin (when increased before or during exercise) and exercise on skeletal muscle glucose uptake are additive/synergistic (DeFronzo et al. 1981; Wasserman et al. 1991), but mediated via different mechanisms. Thus, identification of the mechanisms by which exercise increases glucose uptake may lead to optimization of exercise interventions and to novel therapeutic strategies to manage and prevent insulin resistance. Skeletal muscle glucose uptake occurs by facilitated diffusion and there are three sites of regulation: (1) glucose delivery, (2) sarcolemmal glucose transport, mediated by the GLUT4 glucose transporter, and (3) glucose phosphorylation by hexokinase and subsequent metabolism (Wasserman et al. 2011). Although glucose transport is thought to be rate-limiting under resting conditions, the large increases in glucose delivery, secondary to skeletal muscle hyperemia, and glucose transport caused by rapid GLUT4 translocation to surface membranes (Fig. 4) (Kristiansen et al. 1997) mean that glucose phosphorylation becomes an important site of regulation during exercise. This is perhaps most evident during intense exercise (Katz et al. 1986) and the early stages of prolonged exercise when rates of muscle glycogenolysis are at their highest (Katz et al. 1991). That said, glucose delivery remains an important determinant of muscle glucose uptake during exercise (Zinker et al. 1993) and GLUT4 is essential for exercise-induced muscle glucose uptake (Howlett et al. 2013).

Given the fundamental importance of GLUT4 expression and translocation for contraction-stimulated muscle glucose transport, it is not surprising that there has been considerable research undertaken to identify the underlying signals and molecular mechanisms responsible for increased glucose transport during contractions/exercise. Investigators have used numerous in vitro, in situ, and in vivo experimental models in various species, a range of pharmacological inhibitors of critical enzymes, and transgenic and knockout models. Muscle contraction/exercise is a complex stimulus that generates multiple signals, including increased sarcoplasmic $\left[\mathrm{Ca}^{2+}\right]$, mechanical stress/force, metabolic perturbations (increased AMP/ATP and decreased creatine phosphate and glycogen), changes in redox state associated with increased levels of reactive oxygen species (ROS) and increased nitric oxide (NO). In turn, such signals activate various signaling pathways and protein kinases, notably $\mathrm{Ca}^{2+} /$ calmodulin-de-
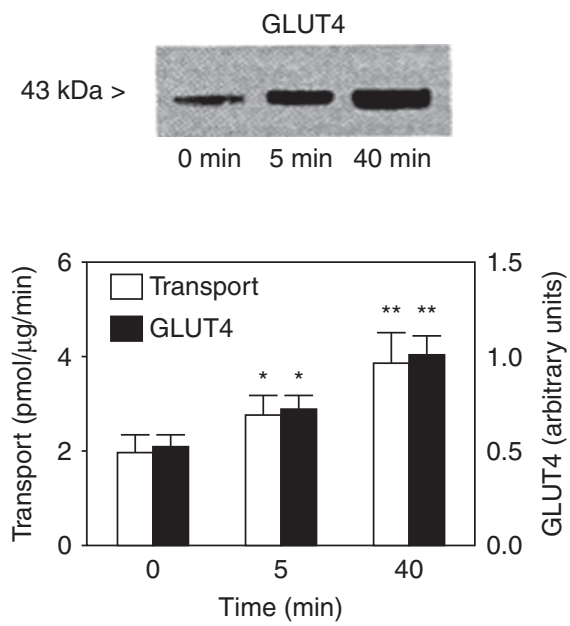

Figure 4. Sarcolemmal vesicle glucose transporter type 4 (GLUT4) expression and glucose transport during exercise. (From Kristiansen et al. 1997; reprinted, with permission, from the authors.) 
pendent protein kinase (CaMK), protein kinase $\mathrm{C}$ (PKC), and AMP-activated protein kinase (AMPK). These kinases act on downstream targets, notably TBC1D1 (tre-2/USP6, BUB2, cdc16 domain family member 1) and AS160 (Akt substrate of $160 \mathrm{kDa}$ or TBC1 domain family member 4-TBC1D4) that are involved in the regulation of GLUT4 vesicle trafficking.

Given the fundamental importance of $\mathrm{Ca}^{2+}$ in muscle contraction, there has been a longstanding view that it also stimulates glucose transport. Studies utilizing caffeine, to induce sarcoplasmic reticulum $\mathrm{Ca}^{2+}$ release, pharmacological CaMK inhibitors, and overexpression of a CaMKII inhibitory peptide in skeletal muscle have implicated $\mathrm{Ca}^{2+}$ in the stimulation of contraction-stimulated muscle glucose transport (Wright et al. 2004; Witczak et al. 2010). In contrast, a recent study has suggested that calcium effects, in the absence of force generation, are mediated via activation of energy-dependent processes within muscle that, in turn, increase AMPK activity and glucose transport (Jensen et al. 2014). These investigators concluded that AMPK activation and mechanical stress, not sarcoplasmic $\mathrm{Ca}^{2+}$ release, were the primary mediators of contraction-stimulated glucose uptake. Another calcium-sensitive kinase is PKC; however, knockout of PKC $\alpha$, the major isoform in skeletal muscle, did not have any effect on contraction-stimulated glucose uptake (Jensen et al. 2009).

AMPK is an important energy-sensing kinase expressed in skeletal muscle that is activated by exercise in an intensity-dependent manner (Friedrichsen et al. 2013; Hardie et al. 2014) and has been implicated in contractionstimulated glucose uptake (Friedrichsen et al. 2013). That said, it has been difficult to conclusively confirm a direct link between AMPK activity and glucose uptake during exercise. The first study to assess this question overexpressed a kinase-dead AMPK mutant in skeletal muscle and observed a reduction in muscle glucose transport during contractions (Mu et al. 2001). Various studies utilizing knockout of the catalytic $\alpha$ subunits of AMPK have produced conflicting results (Friedrichsen et al. 2013), as have studies that have altered activity of the primary upstream kinase liver kinase B1 (LKB1) (Sakamoto et al. 2005; Jeppesen et al. 2013). The latter intervention could have impacted on AMPK, or on other AMPK-related kinases targeted by LKB1 such as sucrose nonfermenting AMPKrelated kinase (SNARK) (Koh et al. 2010). Perhaps the most convincing study is one in which the regulatory $\beta$ subunits of AMPK were ablated, resulting in loss of the catalytic $\alpha$ subunits and marked attenuation of glucose uptake during in vitro muscle contractions and in vivo exercise (O'Neill et al. 2011). Although the definitive evidence confirming the essential role of AMPK in contraction/exercise-stimulated glucose uptake is perhaps lacking, it is teleologically attractive that an energy-sensing kinase would regulate skeletal muscle glucose uptake during exercise.

Other factors involved in the stimulation of glucose uptake during contractions/exercise include ROS (Merry et al. 2010; Katz 2016) and NO (Bradley et al. 1999; Merry et al. 2010). ROS appear to be more important during heavy exercise, because antioxidant treatment did not impact glucose uptake during mild to moderate exercise (Katz 2016), the significance of which remains to be determined. Despite good evidence supporting a role for $\mathrm{NO}$ in stimulating glucose uptake during exercise, the source of $\mathrm{NO}$ and the downstream mechanisms ultimately effecting GLUT4 translocation and increased sarcolemmal glucose transport remain to be fully elucidated (Hong et al. 2014). Mechanical stress/force is a key element of the muscle contraction cycle and recently it has been proposed that the Rho family GTPase Rac1, also associated with the actin cytoskeleton, has an important role in contraction/exercise-stimulated muscle glucose uptake (Sylow et al. 2013) via effects on GLUT4 translocation (Sylow et al. 2016).

Important downstream targets of the above-mentioned signaling cascades are the Rab GTPase-activating proteins TBC1D1 and AS160 that are involved in the interactions between Rab proteins and GLUT4 vesicles during the various events required for translocation of GLUT4 from intracellular sites to the surface membranes. Because insulin and muscle con- 
tractions/exercise result in distinct and different phosphorylation signatures of both these proteins (Kramer et al. 2006; An et al. 2010; Treebak et al. 2014; Cartee 2015), it has been suggested that these proteins may be important sites of convergence of the insulin and contraction/exercise signaling pathways, thereby accounting for the additive effects of these two stimuli and potentially contributing to enhanced muscle insulin sensitivity in the postexercise period (Cartee 2015).

A well-known adaptation to exercise training is a reduction in carbohydrate oxidation during exercise associated with reduced glucose turnover and oxidation, at least at the same absolute power output (Coggan et al. 1990, 1995b). The training effects on glucose turnover are sometimes less apparent during exercise at the same relative exercise intensity (Friedlander et al. 1997), but still existent in cross-sectional comparisons (Coggan et al. 1995a). The decrease in glucose uptake during exercise after training is also associated with a lower liver glucose output because of reductions in both hepatic glycogenolysis and gluconeogenesis (Coggan et al. 1995b). At maximal exercise intensities, there may be an increase in muscle glucose uptake associated with an increased capacity for glucose transport caused by increased muscle GLUT4 protein expression following training (Kristiansen et al. 2000). This increase in GLUT4 expression is also an important factor underlying enhanced muscle insulin sensitivity and muscle glycogen storage in the trained state. The molecular mechanisms responsible for the increase in muscle GLUT4 expression following exercise training include many of the pathways responsible for the increases in glucose transport with acute exercise (for a review, see Richter and Hargreaves 2013).

\section{SKELETAL MUSCLE FATTY ACID OXIDATION}

Our understanding of the regulation of fat metabolism in skeletal muscle during exercise lags behind that of carbohydrate metabolism. Research in the past 15 years has shown that many sites of control are similar in location to that of carbohydrate, including the protein-mediated transport of fat into muscle and the degradation of stored IMTG (Kiens 2006; Glatz et al. 2010; Spriet 2012, 2014). However, other control sites are unique to fat metabolism, including the binding of fat to a protein chaperone and transport in the cytoplasm, and the protein-mediated transport of fat into the mitochondria (Campbell et al. 2004; Bezaire et al. 2006). Later work identified the presence of fat transport proteins in the transverse tubule membranes and translocation of transport proteins to these membranes occurs during exercise (Stefanyk et al. 2012).

Other recent discoveries include the identification of the enzyme adipose tissue glyceride lipase (ATGL) that works in concert with hormone-sensitive lipase (HSL) to regulate skeletal muscle lipolysis (Zimmermann et al. 2004; Watt and Spriet 2010) and the presence of perilipinlike proteins coating the lipid droplets in skeletal muscle (MacPherson and Peters 2015). Another possible site of regulation that has not been explored is control within the $\beta$-oxidation pathway. Last, there is the overarching aspect of the regulation of skeletal muscle fat oxidationthat the mitochondrial volume (the total amount of fat transport and metabolizing proteins) determines the overall capacity to oxidize fat (Perry et al. 2008; Holloway and Spriet 2009).

\section{EXERCISE-INDUCED MUSCLE FATTYY ACID UPTAKE AND FAT TRANSPORT PROTEIN TRANSLOCATION}

Although a small amount of fat can diffuse through the lipid bilayer of the muscle membrane into the muscle cell, it is now widely accepted that the major portion of the FAs that enter muscle do so via protein-mediated mechanisms (Bonen et al. 2007; Holloway et al. 2008; Glatz et al. 2010). This involves actual transport of FA across the muscle membrane by carrier proteins and/or facilitation of their movement across the membrane by initial binding to transport proteins. The major transport proteins include the plasma membrane fatty acid-binding protein $\left(\mathrm{FABP}_{\mathrm{pm}}\right)$ located on the outer leaflet of the plasma membrane, 
M. Hargreaves and L.L. Spriet

a family of fatty acid transport proteins (mainly FATP1, 4) that have many transmembrane domains, and, most importantly, the fatty acid translocase (FAT/CD36) protein that has two transmembrane domains. Much of the pioneering research was performed in red and white rodent skeletal muscle in which the investigators showed a strong relationship between the expression and protein content of the putative transporters and actual FA uptake (Bonen et al. 1998). The messenger RNA (mRNA) abundance and protein content of the FA transporters in the plasma membrane and the FA transport capacity were severalfold higher in red oxidative rodent muscle (high capacity for fat metabolism) versus white glycolytic muscle (Bonen et al. 1998). The transport of FA also appeared to be a saturable process in sarcolemmal vesicles prepared from both red and white rat muscles. This corroborated earlier work in rat hind limb and human skeletal muscle exposed to high FA availability (Turcotte et al. 1991, 1992). Chronic electrical stimulation in rodents and exercise training in humans increased total muscle $\mathrm{FABP}_{\mathrm{pm}}$ and FAT/CD36 protein content and the plasma membrane content of $\mathrm{FABP}_{\mathrm{pm}}$, but not the content of FAT/CD36 (Fig. 5) (Bonen et al. 1999; Talanian et al. 2010).

A critical finding was that FAT/CD36 acutely translocated from an intracellular pool to the muscle membrane in rodent and human skeletal muscle during a single bout of muscle contractions, very similar to GLUT4 (Bonen et al. 2000; Bradley et al. 2012).

It was subsequently shown that muscle contractions also increased the plasma membrane content of $\mathrm{FABP}_{\mathrm{pm}}$, FATP1 and 4 proteins in mouse skeletal muscle (Jain et al. 2009), and that the membrane content of FAT/CD36, $\mathrm{FABP}_{\mathrm{pm}}$, and FATP4 but not FATP1 correlated highly with the capacities for oxidative metabolism and FA oxidation in six different rat skeletal muscles (Nickerson et al. 2009). These investigators then overexpressed each of the four transport proteins independently within a normal physiological range, without affecting the total or plasma membrane content of the other three transport proteins (Nickerson et al. 2009). All transport proteins increased FA transport but FAT/CD36 and FATP4 were two times more effective than $\mathrm{FABP}_{\mathrm{pm}}$, and FATP1 and all trans-
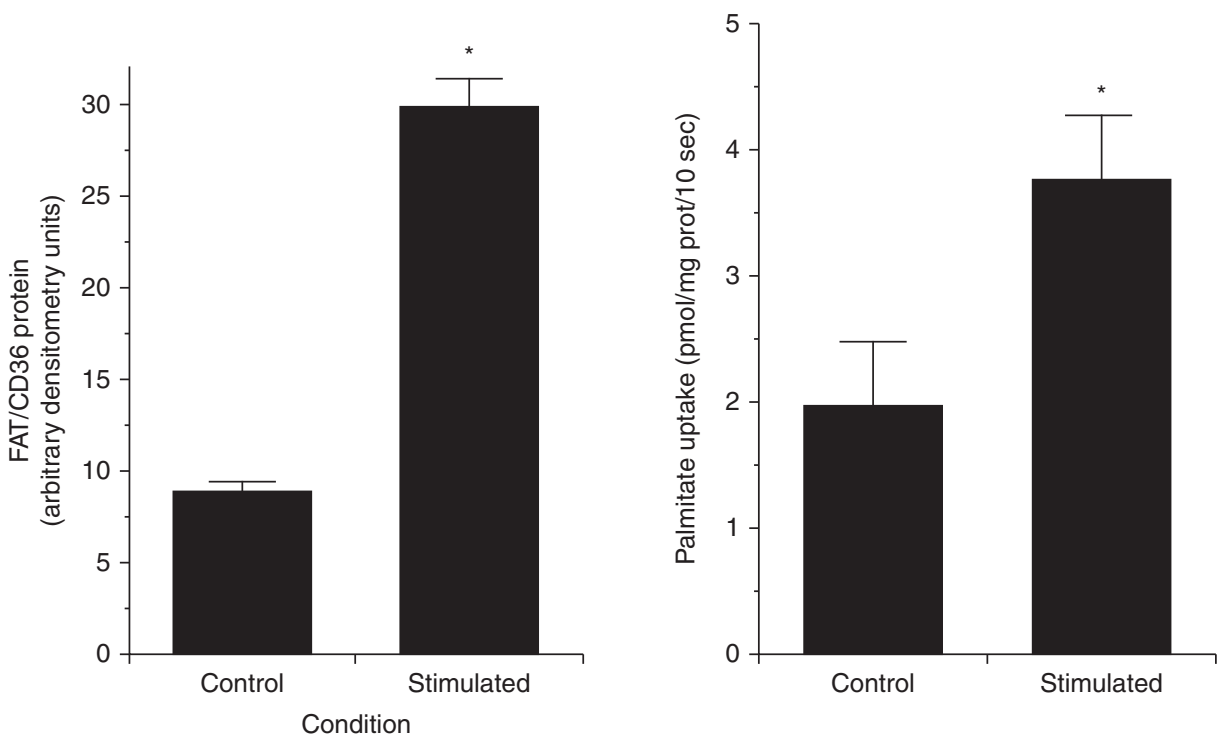

Figure 5. Fatty acid translocase (FAT/CD36) protein expression in and palmitate uptake by giant sarcolemmal vesicles obtained from control and chronically stimulated rat skeletal muscle. (From Bonen et al. 1999; reprinted, with permission, from the American Physiological Society (C) 1999.) 
porters also increased FA oxidation but FAT/ $\mathrm{CD} 36$ and $\mathrm{FABP}_{\mathrm{pm}}$ were three times more effective than FATP1 and 4 (Nickerson et al. 2009). Taken together, these data showed that the movement of fat into skeletal muscle during exercise is a highly regulated process involving several transport proteins that are responsive to both the acute and chronic need for fat as a fuel source. However, there has been less work to clarify the factors that activate the translocation of fat transporter proteins to the muscle membrane during exercise. It is expected that $\mathrm{Ca}^{2+}$ and the factors related to the energy status of the cell (e.g., free ADP, Pi, and AMPK activation) would be involved as they play an important role in activating the transport and docking of GLUT4 into the muscle membrane. However, the time course of the changes involved in upregulating FA uptake and oxidation during exercise is generally believed to be slower than the activation of glucose uptake during exercise. In skeletal muscle, contraction and the activation of muscle AMPK by the pharmacological activator 5-aminoimidazole-4-carboxamide-1$\beta$-D-ribofuranoside (AICAR) produced translocation of both GLUT4 and FAT/CD36 to the sarcolemma, albeit with a different time-course (Cushman et al. 1998; Jain et al. 2009), as well as that of a number of other FA transporters, namely, FABP ${ }_{\text {pm }}$, FATP1, and FATP4 but not FATP6 (Jain et al. 2009). The working hypothesis is that $\mathrm{Ca}^{2+}$ and AMPK play important roles in the translocation of FA transporters to the muscle membrane. Turcotte et al. (2005) showed that inhibition of extracellular regulated kinase $1 / 2$ (ERK1/2), stimulated by $\mathrm{Ca}^{2+}$-dependent PKC, prevented the normal contraction-induced increase in plasma membrane FAT/CD36 content and FA uptake in rodent muscle. A study by Jeppesen et al. (2011) using AMPK $\alpha 2$-null mice suggested that skeletal muscle FAT/CD36 trafficking and FA uptake was independent of AMPK as all responses to contraction and exercise were normal when compared with wild-type skeletal muscles. However, when AMPK $\alpha 1$ and $\alpha 2$ were specifically knocked out in mouse skeletal muscle, animals oxidized less fat during treadmill exercise; muscle isolated from these animals had lower FA oxidation rates when stim- ulated and FAT/CD36 and $\mathrm{FABP}_{\mathrm{pm}}$ contents were also lower (Fentz et al. 2016). These results suggest that AMPK $\alpha$ was required for normal FA metabolism during muscle contractions and exercise (Fentz et al. 2016). Another recent report showed that mice with a muscle-specific knockout of LKB1 had decreased FA oxidation during treadmill exercise and decreased expression of genes involved in FA oxidation (Jeppesen et al. 2013). As LKB1 is upstream of AMPK, it may also influence FA metabolism independently of AMPK in skeletal muscle.

As discussed earlier, Akt is a family of protein kinases regulating multiple anabolic pathways with three isoforms described. Akt2 is involved in insulin signaling and contributes to the regulation of lipid metabolism. However, it is not known whether the regulation of lipid metabolism by Akt2 signaling extends to the FA transport process. In muscle from Akt2knockout mice, Akt2 was important for normal contraction-induced FA transport and translocation of FAT/CD36 and FATP1, but not translocation of $\mathrm{FABP}_{\mathrm{pm}}$ and FATP4 (Jain et al. 2015). Instead, Akt 2 mediated intracellular retention of FABP ${ }_{\mathrm{pm}}$ and FATP4. It has also been shown that MUNC18c, which is present in skeletal muscle plasma membrane and has binding specificity for the tSNARE protein syntaxin 4 and which plays a role in GLUT4 trafficking, is not involved in FA trafficking in skeletal muscle (Jain et al. 2012).

One last point warrants mentioning. The long-held view in skeletal muscle has been that the mitochondrial volume or the total amount of fat transport and metabolizing proteins determines the overall capacity to oxidize fat (Perry et al. 2008; Holloway and Spriet 2009). However, this point of view has been recently challenged by reports showing that up-regulation of sarcolemmal FAT/CD36 protein in rodent skeletal muscle increases FA uptake and oxidation and whole-body exercise performance independent of changes in mitochondrial content or machinery (McFarlan et al. 2012; Yoshida et al. 2013). What needs to be determined is whether these changes occur independently in an intact whole-body situation. In summary, there is much work to be performed 
M. Hargreaves and L.L. Spriet

to elucidate the contractile-induced signals and mechanisms responsible for the movement of FA transporters to the muscle membrane and transverse tubules in skeletal muscle in response to acute and chronic exercise (Turcotte and Abbott 2012).

\section{EXERCISE-INDUCED INTRAMUSCULAR TRIGLYCERIDE BREAKDOWN}

Skeletal muscle has a large amount of stored fat in lipid droplets, especially in physically trained individuals. This IMTG or intramyocellular lipid (IMCL) can be degraded and used as an aerobic fuel during low to moderate exercise (Fig. 3), as has been shown many times (Romijn et al. 1993; Stellingwerff et al. 2007; Loher et al. 2016). The key enzymes involved in regulating lipolysis in skeletal muscle are ATGL, HSL, and monoglyceride lipase (MGL) that sequentially remove an FA from the triglyceride (TG) stored in lipid droplets. ATGL and HSL are highly regulated, whereas MGL is not (Watt 2009; Watt and Spriet 2010; Alsted et al. 2013). It is also important to note that other factors play a role in TG breakdown, including droplet size, droplet localization, and the fact that lipid is stored in droplets with a protein (perilipins) coating (Loher et al. 2016). The perilipin proteins appear to separate IMTG from ATGL and HSL, maintaining low rates of lipolysis at rest. During moderate-intensity exercise, $\mathrm{Ca}^{2+}$ and adrenaline-related events phosphorylate HSL (Watt et al. 2003; Talanian et al. 2006) and AMPK phosphorylation of perilipin is involved in recruiting both HSL and ATGL to the lipid droplet, collectively enhancing rates of IMTG hydrolysis (Prats et al. 2006). However, at higher power outputs, it appears that AMPK phosphorylates additional sites on HSL that inhibit the phosphorylation by adrenaline and $\mathrm{Ca}^{2+}$, providing a potential mechanism for the lower rates of IMTG use reported at these higher intensities (Watt et al. 2003). This explanation of events during exercise does not include a role for ATGL in skeletal muscle, but work in this area is ongoing. It has been recently shown that ATGL content increased in rodent and human skeletal muscle with exercise training (Alsted et al. 2009; Turnbull et al. 2016). It was also implicated to play a significant role during exercise, as lipolysis was maintained when HSL was pharmacologically inhibited or knocked out in rodent skeletal muscle (Alsted et al. 2013). ATGL is activated by association with a protein called comparative gene identification58 (CGI-58) and putatively inhibited by G(0)/ G(1) switch gene-2 protein (G0S2) (MacPherson et al. 2013a; Turnbull et al. 2015, 2016). There was the early suggestion that the relative amount of CGI-58-to-ATGL and G0S2-toATGL protein controlled the regulation of ATGL. However, recent work with rodent muscles of varying oxidative potentials at rest, during contraction, and following training did not support this contention, suggesting that regulation must occur through more complicated mechanisms (Turnbull et al. 2015, 2016).

Perilipin 1 (PLIN1) is a member of the lipid droplet-associated (PLIN) family of proteins that is involved in the storage and mobilization and use of FAs in cells. PLIN1 has been implicated in regulating lipolysis in adipose tissue by interacting with the TG lipases. However, a recent review reported that PLIN1 is not found in skeletal muscle and it is not clear whether any of the PLINs found in skeletal muscle (PLIN2, 3, and 5) are involved in regulating lipolysis in a manner similar to PLIN1 in adipose tissue (MacPherson and Peters 2015). These investigators cited evidence that all three skeletal muscle PLINs interact with HSL and may regulate the location of HSL or its activity on the surface of the lipid droplet (MacPherson et al. 2013a,b). Interestingly, all three PLINs also interact with ATGL, PLIN3 and 5 interact with CGI-58, and it has been suggested that they act as locating and scaffolding proteins for ATGL until a lipolytic stimulus appears (MacPherson and Peters 2015). However, these investigators point out that PLIN5 is also associated with and translocates to the mitochondria suggesting that it may play a role in the regulation of FA oxidation and not IMTG lipolysis.

In summary, although it is clear that IMTG lipolysis plays an important role in providing FA for oxidation during exercise (Fig. 3), understanding the regulation that occurs at the level 
of the lipid droplet for FAs to be released and delivered to the surface of the mitochondria remains largely unknown.

\section{EXERCISE-INDUCED MUSCLE MITOCHONDRIAL FATTY ACID UPTAKE AND FAT TRANSPORTER TRANSLOCATION}

The transport of FAs into mitochondria is a key step in regulating the overall rate that skeletal muscle can oxidize FAs (Holloway et al. 2008; Smith et al. 2012b). At one time, the regulation of FA oxidation at the level of mitochondria was solely attributed to the relationship between carnitine palmitoyl transferase (CPT)I activity and malonyl-CoA (M-CoA) (McGarry and Brown 1997). In rodent skeletal muscle at rest, M-CoA levels are highest and believed to inhibit the transfer of FAs through the CPT complex into the mitochondria. On contraction, the $\mathrm{M}-\mathrm{CoA}$ content decreased and relieved the inhibition on the CPT complex (reviewed in Spriet 2012, 2014). M-CoA has also been detected in human skeletal muscle, and measurements at rest and during exercise have shown that M-CoA content is unaffected by exercise at varying power outputs $\left(35 \%-100 \% \mathrm{VO}_{2 \max }\right)$ and rates of fat oxidation (Odland et al. 1998) or decreases slightly during prolonged exercise (Roepstorff et al. 2005). Recent work using permeabilized skeletal muscle fibers showed that M-CoA inhibition of CPT1 is dependent on the palmitoyl-CoA content (Smith et al. 2012a). This suggests that an increase in skeletal muscle palmitoyl-CoA content at the onset of exercise could override any inhibitory effect of M-CoA and allow FA transport and oxidation to proceed.

In keeping with the suggestion that the regulation of CPTI activity and FA transport across the mitochondrial membranes was more complex, was the finding that FAT/CD36 also existed on the skeletal muscle mitochondrial membranes (Campbell et al. 2004; Bezaire et al. 2006). It was also shown that, although $\mathrm{FABP}_{\mathrm{pm}}$ facilitated FA transport at the sarcolemma, it played no role at the mitochondria (Holloway et al. 2007). FAT/CD36 appeared to regulate mitochondrial FA oxidation as FA oxidation rates were lower in animals with no FAT/ CD36 (Holloway et al. 2009). In human skeletal muscle, moderate-intensity exercise acutely increased the mitochondrial membrane FAT/ CD36 protein content and mitochondrial FA oxidation (Holloway et al. 2006). In other experiments, FAT/CD36 coimmunoprecipitated with CPTI (Schenk and Horowitz 2006) and exercise training increased the FAT/CD36 content on the mitochondria membranes to a greater extent than the increase in mitochondrial volume (Talanian et al. 2010). There has been little work examining the regulation of FAT/ CD36 movement to the mitochondrial membranes during exercise, as it would be assumed that the system controlling movement to the sarcolemma would also control movement to the mitochondria. In one study, Monaco et al. (2015) reported that AMPK $\alpha 2$ was not required for skeletal muscle mitochondrial FAT/CD36 accumulation in AMPK $\alpha 2$ dead mice during exercise. Smith et al. (2011, 2012b) proposed a theory describing a dual mechanism of action for skeletal muscle FAT/CD36 during exercise, acting at both the muscle and mitochondrial membranes to increase FA transport into the muscle and mitochondria. Details suggest that FAT/CD36 is located on the outer mitochondrial membrane upstream of the acyl-CoA synthase enzyme. This location, in some unexplained manner, appears to facilitate the delivery of long-chain fatty acid (LCFA) to this enzyme so it can proceed through the reaction and the CPT complex and into the mitochondria (Smith et al. 2011). This research does not downplay the importance of the CPT complex in mitochondrial FA transport, but rather indicates a complexity in the regulation of mitochondrial FA transport not previously understood.

\section{CONCLUDING REMARKS}

Our understanding of exercise metabolism and the interplay between carbohydrate and fat metabolism, including underlying regulatory mechanisms, has increased over the years based on studies utilizing various methods, including indirect calorimetry, metabolic tracers sampling, and analysis of blood and tissue samples 
M. Hargreaves and L.L. Spriet

from contracting skeletal muscle. In an era of expanding tools in genomics, epigenomics, transcriptomics, proteomics, and metabolomics, along with system and computational biology approaches to data analysis, new insights should be obtained on substrate fluxes in metabolically active tissues and the molecular regulation of exercise metabolism.

\section{REFERENCES}

Allen DG, Lamb GD, Westerbald H. 2008. Skeletal muscle fatigue: Cellular mechanisms. Physiol Rev 88: 287-332.

Alsted TJ, Nybo L, Schweiger M, Fledelius C, Jacobsen P, Zimmermann R, Zechner R, Kiens B. 2009. Adipose triglyceride lipase in human skeletal muscle is upregulated by exercise training. Am J Physiol 296: E445-E453.

Alsted TJ, Ploug T, Prats C, Serup AK, Høeg L, Schjerling P, Holm C, Zimmermann R, Fledelius C, Galbo H, et al. 2013. Contraction-induced lipolysis is not impaired by inhibition of hormone-sensitive lipase in skeletal muscle. J Physiol 591: 5141-5155.

An D, Toyoda T, Taylor EB, Yu H, Fujii N, Hirshman MF, Goodyear LJ. 2010. TBC1D1 regulates insulin- and contraction-induced glucose transport in mouse skeletal muscle. Diabetes 59: 1358-1365.

Bezaire V, Bruce CR, Heigenhauser GJ, Tarendon NN, Glatz JFC, Luiken JJJF, Bonen A, Spriet LL. 2006. Identification of fatty acid translocase on human skeletal muscle mitochondrial membranes: Essential role in fatty acid oxidation. Am J Physiol 290: E509-E515.

Bonen A, Luiken JJFP, Liu S, Dyck DJ, Kiens B, Kristiansen S, Turcotte LP, Van Der Vusse GJ Glatz JF. 1998. Palmitate transport and fatty acid transporters in red and white muscles. Am J Physiol 275: E471-E478.

Bonen A, Dyck DJ, Ibrahimi A, Abumrad NA. 1999. Muscle contractile activity increases fatty acid metabolism and transport and FAT/CD36. Am J Physiol 276: E642-E649.

Bonen A, Luiken JJFP, Arumugam T, Glatz JF, Tandon NN. 2000. Acute regulation of fatty acid uptake involves the cellular redistribution of fatty acid translocase. $J$ Biol Chem 275: 14501-14508.

Bonen A, Chabowski A, Luiken JJFP, Glatz JF. 2007. Is membrane transport of FFA mediated by lipid, protein, or both? Mechanisms and regulation of protein-mediated cellular fatty acid uptake: Molecular, biochemical, and physiological evidence. Physiologist 22: 15-29.

Bradley SJ, Kingwell BA, McConell GK. 1999. Nitric oxide synthase inhibition reduces leg glucose uptake but not blood flow during dynamic exercise in humans. Diabetes 48: $1815-1821$.

Bradley NS, Snook LA, Jain SS, Heigenhauser, GJF, Bonen A, Spriet LL. 2012. Acute endurance exercise increases plasma membrane fatty acid transport proteins in rat and human skeletal muscle. Am J Physiol 302: E183-E189.

Brooks GA. 2009. Cell-cell and intracellular lactate shuttles. J Physiol 587: 5591-5600.
Campbell, Tandon NN, Woldegiorgis G, Luiken JJFP, Glatz JFC, Bonen A. 2004. A novel function for fatty acid translocase (FAT)/CD36. J Biol Chem 279: 36235-36241.

Cartee GD. 2015. Roles of TBC1D1 and TBC1D4 in insulinand exercise-stimulated glucose transport of skeletal muscle. Diabetologia 58: 19-30.

Casey A, Constantin-Teodosiu D, Howell S, Hultman E, Greenhaff PL. 1996. Metabolic responses of type I and II muscle fibres during repeated bouts of maximal exercise in humans. Am J Physiol 271: E38-E43.

Cermak NM, van Loon LJ. 2013. The use of carbohydrates during exercise as an ergogenic aid. Sports Med 43: 1139 1155.

Coggan AR, Kohrt WM, Spina RJ, Bier DM, Holloszy JO. 1990. Endurance training decreases plasma glucose turnover and oxidation during moderate-intensity exercise in men. J Appl Physiol 68: 990-996.

Coggan AR, Raguso CA, Williams BD, Sidossis LS, Gastaldelli A. 1995a. Glucose kinetics during high-intensity exercise in endurance-trained and untrained humans. $J$ Appl Physiol 78: 1203-1207.

Coggan AR, Swanson SC, Mendenhall LA, Habash DL, Kien CL. 1995b. Effect of endurance training on hepatic glycogenolysis and gluconeogenesis during prolonged exercise in men. Am J Physiol 268: E375-E383.

Cushman SW, Goodyear LJ, Pilch PF, Ralston E, Galbo H, Ploug T, Kristiansen S, Klip A. 1998. Molecular mechanisms involved in GLUT4 translocation in muscle during insulin and contraction stimulation. Adv Exp Med Biol 441: 63-71.

DeFronzo RA, Ferrannini E, Sato Y, Wahren J. 1981. Synergistic interaction between exercise and insulin on peripheral glucose uptake. J Clin Invest 68: 1468-1474.

Fentz J, Kjobsted R, Birk JB, Jeppesen J, Thorsen K, Schjerling P, Kiens B, Jessen N, Viollet B, Wojtaszewski JF. 2016. AMPK $\alpha$ is critical for enhancing skeletal muscle fatty acid utilization during in vivo exercise in mice. FASEB J 29: 1725-1738.

Friedlander AL, Casazza GA, Horning MA, Huie MJ, Brooks GA. 1997. Training-induced alterations of glucose flux in men. J Appl Physiol 82: 1360-1369.

Friedrichsen M, Mortenson B, Pehmøller C, Birk JB, Wojtaszewski JFP. 2013. Exercise-induced AMPK activity in skeletal muscle: Role in glucose uptake and insulin sensitivity. Mol Cell Endocrinol 366: 204-214.

Glatz JF, Luiken JJ, Bonen A. 2010. Membrane fatty acid transporters as regulators of lipid metabolism: Implications for metabolic disease. Physiol Rev 90: 367-417.

Hardie DG, Ross FA, Hawley SA. 2012. AMPK: A nutrient and energy sensor that maintains energy homeostasis. Nat Rev Mol Cell Biol 13: 251-262.

Hargreaves M, McKenna MJ, Jenkins DG, Warmington SA, Li JL, Snow RJ, Febbraio MA. 1998. Muscle metabolites and performance during high intensity, intermittent exercise. J Appl Physiol 84: 1687-1691.

Hawley JA, Schabort EJ, Noakes TD, Dennis SC. 1997. Carbohydrate-loading and exercise performance: An update. Sports Med 24: 73-81.

Hawley JA, Hargreaves M, Joyner MJ, Zierath JR. 2014. Integrative biology of exercise. Cell 159: 738-749. 
Holloway GP, Spriet LL. 2009. Skeletal muscle metabolic adaptations to training. In The IOC textbook of science in sport, 1st ed. (ed. Maughan RJ), pp. 70-83. WileyBlackwell, Oxford.

Holloway GP, Bezaire V, Heigenhauser GJF, Tarendon NN, Glatz JFC, Luiken JJFP, Bonen A, Spriet LL. 2006. Mitochondrial long chain fatty acid oxidation, fatty acid translocase/CD36 content and carnitine palmitoyltransferase I activity in human skeletal muscle during aerobic exercise. J Physiol 571: 201-210.

Holloway GP, Lally J, Nickerson JG, Alkhateeb H, Snook LA, Heigenhauser GJF, Calles-Escandon J, Glatz JFC, Luiken JJFP, Spriet LL, et al. 2007. Fatty acid binding protein facilitates sarcolemmal fatty acid transport but not mitochondrial oxidation in rat and human skeletal muscle. $J$ Physiol 582: 393-405.

Holloway GP, Luiken JJFP, Glatz JF, Spriet LL, Bonen A 2008. Contribution of FAT/CD36 to the regulation of skeletal muscle fatty acid oxidation: An overview. Acta Physiol 194: 293-309.

Holloway GP, Jain SS, Bezaire V, Han XX, Glatz JF, Luiken JJ, Harper ME, Bonen A. 2009. FAT/CD36 null mice reveal that mitochondrial FAT/CD36 is required to up-regulate mitochondrial fatty acid oxidation in contracting muscle. Am J Physiol 297: R960-R967.

Hong YH, Betik AC, McConell GK. 2014. Role of nitric oxide in skeletal muscle glucose uptake during exercise. Exp Physiol 99: 1569-1573.

Howlett RA, Parolin ML, Dyck DJ, Hultman E, Jones NL, Heigenhauser GJF, Spriet LL. 1998. Regulation of skeletal muscle glycogen phosphorylase and $\mathrm{PDH}$ at varying exercise power outputs. Am J Physiol 275: R418-R425.

Howlett KF, Andrikopoulos S, Proietto J, Hargreaves M. 2013. Exercise-induced muscle glucose uptake in mice with graded, muscle-specific GLUT-4 deletion. Physio Rep 1: 1-7.

Jain SS, Chabowski A, Snook LA, Schwenk RW, Glatz JFC, Luiken JJFP, Bonen A. 2009. Additive effects of insulin and muscle contraction on fatty acid transport and fatty acid transporters, FAT/CD36, FABP ${ }_{\mathrm{pm}}$, FATP1, 4 and 6 . FEBS Lett 583: 2294-2300.

Jain SS, Snook LA, Glatz JF, Luiken JJ, Holloway GP, Thurmond DC, Bonen A. 2012. Munc18c provides stimulusselective regulation of GLUT4 but not fatty acid transporter trafficking in skeletal muscle. FEBS Lett 586: $2428-2435$.

Jain SS, Luiken JJ, Snook LA, Han XX, Holloway GP, Glatz JF, Bonen A. 2015. Fatty acid transport and transporters in muscle are critically regulated by Akt2. FEBS Lett 589: 2769-2775.

Jensen TE, Maarbjerg SJ, Rose AJ, Leitges M, Richter EA. 2009. Knockout of the predominant conventional PKC isoform, $\mathrm{PKC} \alpha$, in mouse skeletal muscle does not affect contraction-stimulated glucose uptake. Am J Physiol 297: E340-E348.

Jensen TE, Sylow L, Rose AJ, Madsen AB, Angin Y, Maarbjerg SJ, Richter EA. 2014. Contraction-stimulated glucose transport in muscle is controlled by AMPK and mechanical stress but not sarcoplasmic reticulum $\mathrm{Ca}^{2+}$ release. Mol Metab 3: 742-753.

Jeppesen J, Albers PH, Rose AJ, Birk JB, Schjerling P, Dzamko N, Steinberg GR, Kiens B. 2011. Contraction- induced skeletal muscle FAT/CD36 trafficking and FA uptake is AMPK independent. J Lipid Res 52: 699-711.

Jeppesen J, Maarbjerg SJ, Jordy AB, Fritzen AM, Pehmøller C, Sylow L, Serup AK, Jessen N, Thorsen K, Prats C, et al. 2013. LKB1 regulates lipid oxidation during exercise independently of AMPK. Diabetes 62: 1490-1499.

Katz A. 2016. Role of reactive oxygen species in regulation of glucose transport in skeletal muscle during exercise. $J$ Physiol 594: 2787-2794.

Katz A, Broberg S, Sahlin K, Wahren J. 1986. Leg glucose uptake during maximal dynamic exercise in humans. Am J Physiol 251: E65-E70.

Katz A, Sahlin K, Broberg S. 1991. Regulation of glucose utilization in human skeletal muscle during moderate dynamic exercise. Am J Physiol 260: E411-E415.

Kiens B. 2006. Skeletal muscle lipid metabolism in exercise and insulin resistance. Physiol Rev 86: 205-243.

Koh HJ, Toyoda T, Fujii N, Jung MM, Rathod A, Middelbeek RJ, Lessard SJ, Treebak JT, Tsuchihara K, Esumi H, et al. 2010. Sucrose nonfermenting AMPK-related kinase (SNARK) mediates contraction-stimulated glucose transport in mouse skeletal muscle. Proc Natl Acad Sci 107: 15541-15546.

Kramer HF, Witczak CA, Taylor EB, Fujii N, Hirshman MF, Goodyear LJ. 2006. AS160 regulates insulin- and contraction-stimulated glucose uptake in mouse skeletal muscle. J Biol Chem 281: 31478-31485.

Kristiansen S, Hargreaves M, Richter EA. 1997. Progressive increase in glucose transport and GLUT-4 in human sarcolemmal vesicles during moderate exercise. Am J Physiol 272: E385-E389.

Kristiansen S, Gade J, Wojtaszewski JF, Kiens B, Richter EA. 2000. Glucose uptake is increased in trained vs. untrained muscle during heavy exercise. J Appl Physiol 89: 11511158.

Loher H, Kreis R, Boesch C, Christ E. 2016. The flexibility of ectopic lipids. Int J Mol Sci 17: E1554.

MacPherson RE, Peters SJ. 2015. Piecing together the puzzle of perilipin proteins and skeletal muscle lipolysis. Appl Physiol Nutr Metab 40: 641-651.

MacPherson RE, Ramos SV, Vandenboom R, Roy BD, Peters SJ. 2013a. Skeletal muscle PLIN proteins, ATGL and CGI58 , interactions at rest and following stimulated contraction. Am J Physiol 304: R644-R650.

MacPherson RE, Vandenboom R, Roy BD, Peters SJ. 2013b. Skeletal muscle PLIN3 and PLIN5 are serine phosphorylated at rest and following lipolysis during adrenergic or contractile stimulation. Physiol Rep 1: e00084.

Martin IK, Katz A, Wahren J. 1995. Splanchnic and muscle metabolism during exercise in NIDDM patients. Am J Physiol 269: E583-E590.

McFarlan JT, Yoshida Y, Jain SS, Snook LA, Lally J, Smith BK, Glatz JF, Luiken JJ, Sayer RA, Tupling AR, et al. 2012. In vivo, fatty acid translocase (CD36) critically regulates skeletal muscle fuel selection, exercise performance, and training-induced adaptation of fatty acid oxidation. J Biol Chem 287: 23502-23516.

McGarry JD, Brown NF. 1997. The mitochondrial carnitine palmitoyltransferase system. From concept to molecular analysis. Eur J Biochem 244: 1-14. 
Medbø JI, Sejersted OM. 1990. Plasma potassium changes with high intensity exercise. J Physiol 421: 105-122.

Merry TL, Steinberg GR, Lynch GS, McConell GK. 2010. Skeletal muscle glucose uptake during contraction is regulated by nitric oxide and ROS independently of AMPK. Am J Physiol 298: E577-E585.

Monaco C, Whitfield, J, Jain SS, Spriet LL, Bonen A, Holloway GP. 2015. Acitvation of AMPK $\alpha 2$ is not required for mitochondrial FAT/CD36 accumulation during exercise. PLoS ONE 12: e0126122.

Mu J, Brozinick JT, Valladares O, Bucan M, Birnbaum MJ. 2001. A role for AMP-activated protein kinase in contraction-and hypoxia-regulated glucose transport in skeletal muscle. Mol Cell 7: 1085-1094.

Nickerson JG, Alkhateeb H, Benton CR, Lally J, Nickerson J, Han XX, Wilson MH, Jain SS, Snook LA, Glatz JFC, et al. 2009. Greater transport efficiencies of the membrane fatty acid transporters FAT/CD36 and FATP4 compared with $\mathrm{FABP}_{\mathrm{pm}}$ and FATP1 and differential effects on fatty acid esterification and oxidation in rat skeletal muscle. $J$ Biol Chem 284: 16522-16530.

Odland LM, Howlett RA, Heigenhauser GJF, Hultman E, Spriet LL. 1998. Skeletal muscle malonyl-CoA content at the onset of exercise at varying power outputs in humans. Am J Physiol 274: E1080-E1085.

O’Neill HM, Maarbjerg SJ, Crane JD, Jeppesen J, Jørgensen SB, Schertzer JD, Shyroka O, Kiens B, van Denderen BJ, Tarnopolsky MA, et al. 2011. AMP-activated protein kinase (AMPK) $\beta 1 \beta 2$ muscle null mice reveal an essential role for AMPK in maintaining mitochondrial content and glucose uptake during exercise. Proc Natl Acad Sci 108: $16092-16097$.

Parolin ML, Chesley A, Matsos MP, Spriet LL, Jones NL, Heigenhauser GJF. 1999. Regulation of glycogen phosphorylase and PDH during maximal intermittent exercise. Am J Physiol 277: E890-E900.

Perry CGR, Heigenhauser GJF, Bonen A, Spriet LL. 2008. High-intensity aerobic interval training increases fat and carbohydrate metabolic capacities in human skeletal muscle. Appl Physiol Nutr Metab 33: 1112-1123.

Prats C, Donsmark M, Qvortrup K, Londos C, Sztalryd C, Holm C, Galbo H, Ploug T. 2006. Decrease in intramuscular lipid droplets and translocation of HSL in response to muscle contraction and epinephrine. Lipid Res 47: 2392-2399.

Richter EA, Hargreaves M. 2013. Exercise, GLUT4 and skeletal muscle glucose uptake. Physiol Rev 93: 993-1017.

Roepstorff C, Halberg N, Hillig T, Saha A, Ruderman NB, Wojtaszewski JF, Richter EA, Kiens B. 2005. Malonyl-CoA and carnitine in regulation of fat oxidation in human skeletal muscle during exercise. Am J Physiol 288: E133-E142.

Romijn JA, Coyle EF, Sidossis LS, Gastaldelli A, Horowitz JF, Endert E, Wolfe RR. 1993. Regulation of endogenous fat and carbohydrate metabolism in relation to exercise intensity and duration. Am J Physiol 265: E380-E391.

Romijn JA, Coyle EF, Sidossis LS, Zhang XJ, Wolfe RR. 1995. Relationship between fatty acid delivery and fatty acid oxidation during strenuous exercise. J Appl Physiol 79: 1939-1945.

Sakamoto K, McCarthy A, Smith D, Green KA, Hardie DG, Ashworth A, Alessi DR. 2005. Deficiency of LKB1 in skel- etal muscle prevents AMPK activation and glucose uptake during contraction. EMBO J 24: 1810-1820.

Schenk S, Horowitz JF. 2006. Coimmunoprecipitation of FAT/CD36 and CPT I in skeletal muscle increases proportionally with fat oxidation after endurance exercise training. Am J Physiol 291: E254-E260.

Smith BK, Jain SS, Rimbaud S, Dam A, Quadrilatero J, Ventura-Clapier R, Bonen A, Holloway GP. 2011. FAT/ CD36 is located on the outer mitochondrial membrane, upstream of long-chain acyl-CoA synthetase, and regulates palmitate oxidation. Biochem J 437: 125-134.

Smith BK, Perry CG, Koves TR, Wright DC, Smith JC, Neufer PD, Muoio DM, Holloway GP. 2012a. Identification of a novel malonyl-CoA IC $_{50}$ for CPT-1: Implications for predicting in vivo fatty acid oxidation rates. Biochem $J$ 448: $13-20$.

Smith BK, Bonen A, Holloway GP. 2012b. A dual mechanism of action for skeletal muscle FAT/CD36 during exercise. Exerc Sport Sci Rev 40: 211-217.

Spriet LL. 2012. The metabolic systems: Lipid metabolism. In Advanced exercise physiology, 2nd ed. (ed. Farrell PA, Joyner MJ, Caiozzo VJ), pp. 392-407. Lippincott Williams \& Wilkins, Philadelphia.

Spriet LL. 2014. New insights into the interaction of carbohydrate and fat metabolism during exercise. Sports Med 44: S87-S96.

Spriet LL, Lindinger MI, McKelvie RS, Heigenhauser GJF, Jones NL. 1989. Muscle glycogenolysis and $\mathrm{H}^{+}$concentration during maximal intermittent cycling. J Appl Physiol 66: 8-13.

Spriet LL, Howlett RA, Heigenhauser GJ. 2000. An enzymatic approach to lactate production in human skeletal muscle during exercise. Med Sci Sports Exerc 32: 756-763.

Stefanyk LE, Bonen A, Dyck DJ. 2012. Insulin and contraction-induced movement of fatty acid transport proteins to skeletal muscle transverse tubules is distinctly different than to the sarcolemma. Metabolism 61: 1518-1522.

Stellingwerff T, Boon H, Jonkers RA, Senden JM, Spriet LL, Koopman R, van Loon LJC. 2007. Significant intramyocellular lipid use during prolonged cycling in endurancetrained males as assessed by three different methodologies. Am J Physiol 292: E1715-E1723.

Sylow L, Jensen TE, Kleinert M, Mouatt JR, Maarbjerg SJ, Jeppesen J, Prats C, Chiu TT, Boguslavsky S, Klip A, et al. 2013. Racl is a novel regulator of contraction-stimulated glucose uptake in skeletal muscle. Diabetes 62: 11391151.

Sylow L, Nielsen IL, Kleinert M, Møller LLV, Ploug T, Schjerling P, Bilan PJ, Klip A, Jensen TE, Richter EA. 2016. Racl governs exercise-stimulated glucose uptake in skeletal muscle through regulation of GLUT4 translocation in mice. J Physiol 594: 4997-5008.

Talanian JL, Tunstall RJ, Watt MJ, Duong M, Perry CGR, Steinberg GR, Kemp BE, Heigenhauser GJF, Spriet LL. 2006. $\beta$-Adrenergic regulation of human skeletal muscle hormone sensitive lipase activity during exercise onset. Am J Physiol 291: R1094-R1099.

Talanian JL, Holloway GP, Snook L, Heigenhauser GJF, Bonen A, Spriet LL. 2010. Exercise training increases sarcolemmal and mitochondrial fatty acid transport proteins in human skeletal muscle. Am J Physiol 299: E180-E188. 
Treebak JT, Pehmøller C, Kristensen JM, Kjøbsted R, Birk JB, Schjerling P, Richter EA, Goodyear LJ, Wojtaszewski JFP. 2014. Acute exercise and physiological insulin induce distinct phosphorylation signatures on TBC1D1 and TBC1D4 proteins in human skeletal muscle. J Physiol 592: $351-375$.

Turcotte LP, Abbott MJ. 2012. Contraction-induced signaling: Evidence of convergent cascades in the regulation of muscle fatty acid metabolism. Can J Physiol Pharmacol 90: 1419-1433.

Turcotte L, Kiens B, Richter EA. 1991. Saturation kinetics of palmitate uptake in perfused skeletal muscle. FEBS Lett 279: 327-329.

Turcotte L, Richter EA, Kiens B. 1992. Increased plasma FFA uptake and oxidation during prolonged exercise in trained vs. untrained humans. Am J Physiol 262: E791-E799.

Turcotte LP, Raney MA, Todd MK. 2005. ERK1/2 inhibition prevents contraction-induced increase in plasma membrane FAT/CD36 content and FA uptake in rodent muscle. Acta Physiol Scand 184: 131-139.

Turnbull PC, Ramos SV, MacPherson REK, Roy BD, Peters SJ. 2015. Characterization of lipolytic inhibitor $\mathrm{G}(0)$ / G(1) switch gene-2 protein (G0S2) expression in male Sprague Dawley rat skeletal muscle compared to relative content of adipose triglyceride lipase (ATGL) and comparative gene-idetification-58 (CGI-58). PLOS ONE 10: e120136.

Turnbull PC, Longo AB, Ramos SV, Roy BD, Ward WE, Peters SJ. 2016. Increases in skeletal muscle ATGL and its inhibitor G0S2 following 8 weeks of endurance training in metabolically different rat skeletal muscles. Am J Physiol 310: R125-R133.

van Loon LJC, Greenhaff PL, Constantin-Teodosiu D, Saris WHM, Wagenmakers AJM. 2001. The effects of increasing exercise intensity on muscle fuel utilisation in humans. J Physiol 536: 295-304.

Wasserman DH, Geer RJ, Rice DE, Bracy D, Flakoll PJ, Brown LL, Hill JO, Abumrad NN. 1991. Interaction of exercise and insulin action in humans. Am J Physiol 260: E37-E45.
Wasserman DH, Kang L, Ayala JE, Fueger PT, Lee-Young RS. 2011. The physiological regulation of glucose flux into muscle in vivo. J Exp Biol 214: 254-262.

Watt MJ. 2009. Triglyceride lipases alter fuel metabolism and mitochondrial gene expression. Appl Physiol Nutr Metab 34: $340-347$.

Watt M, Spriet LL. 2010. Triacylglycerol lipases and metabolic control: Implications for health and disease. $A m J$ Physiol 299: E162-E168.

Watt MJ, Howlett KF, Febbraio MA, Spriet LL, Hargreaves M. 2001. Adrenaline increases skeletal muscle glycogenolysis, PDH activation and carbohydrate oxidation during moderate exercise in humans. J Physiol 534: 269-278.

Watt MJ, Heigenhauser GJF, Spriet LL. 2003. Effects of dynamic exercise intensity on the activation of hormonesensitive lipase in human skeletal muscle. J Physiol 547: 301-308.

Witczak CA, Jessen N, Warro DM, Toyoda T, Fujii N, Anderson ME, Hirshman MF, Goodyear LJ. 2010. CaMKII regulates contraction- but not insulin-induced glucose uptake in mouse skeletal muscle. Am J Physiol 298: E1150-E1160.

Wright DC, Hucker KA, Holloszy JO, Han DH. 2004. $\mathrm{Ca}^{2+}$ and AMPK both mediate stimulation of glucose transport by muscle contractions. Diabetes 53: 330-335.

Yoshida Y, Jain SS, McFarlan JT, Snook LA, Chabowski A, Bonen A. 2013. Exercise- and training-induced upregulation of skeletal muscle fatty acid oxidation are not solely dependent on mitochondrial machinery and biogenesis. J Physiol 591: 4415-4426.

Zimmermann R, Strauss JG, Haemmerle G, Schoiswohl G, Birner-Gruenberger R, Riederer M, Lass A, Neuberger G, Eisenhaber F, Hermetter A, et al. 2004. Fat mobilization in adipose tissue is promoted by adipose triglyceride lipase. Science 306: 1383-1386.

Zinker BA, Lacy DB, Bracy DP, Wasserman DH. 1993. Role of glucose and insulin loads to exercising limb in increasing glucose uptake and metabolism. J Appl Physiol 74: 2915-2922. 


\section{$\&_{\mathrm{CSH}}^{\infty} \&$ Cold Spring Harbor

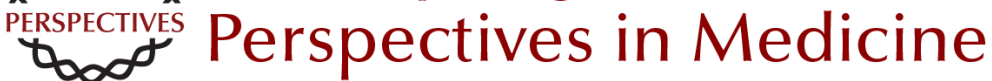

\section{Exercise Metabolism: Fuels for the Fire}

Mark Hargreaves and Lawrence L. Spriet

Cold Spring Harb Perspect Med 2018; doi: 10.1101/cshperspect.a029744 originally published online May 22, 2017

\section{Subject Collection The Biology of Exercise}

Exosomes as Mediators of the Systemic

Adaptations to Endurance Exercise Adeel Safdar and Mark A. Tarnopolsky

Molecular Basis of Exercise-Induced Skeletal

Muscle Mitochondrial Biogenesis: Historical

Advances, Current Knowledge, and Future

Challenges

Christopher G.R. Perry and John A. Hawley

Exercise Metabolism: Fuels for the Fire Mark Hargreaves and Lawrence L. Spriet

Health Benefits of Exercise Gregory N. Ruegsegger and Frank W. Booth

Molecular Regulation of Exercise-Induced Muscle

Fiber Hypertrophy

Marcas M. Bamman, Brandon M. Roberts and Gregory R. Adams

Physiological Redundancy and the Integrative

Responses to Exercise Michael J. Joyner and Jerome A. Dempsey

On the Run for Hippocampal Plasticity C'iana Cooper, Hyo Youl Moon and Henriette van Praag

Molecular Basis for Exercise-Induced Fatigue: The Importance of Strictly Controlled Cellular $\mathrm{Ca}$

2+ Handling

Arthur J. Cheng, Nicolas Place and Håkan

Westerblad
Effects of Exercise and Aging on Skeletal Muscle Giovanna Distefano and Bret $H$. Goodpaster

Muscle-Adipose Tissue Cross Talk Kristin I. Stanford and Laurie J. Goodyear

Performance Fatigability: Mechanisms and Task Specificity

Sandra K. Hunter

Adaptations to Endurance and Strength Training David C. Hughes, Stian Ellefsen and Keith Baar

The Bioenergetics of Exercise

$P$. Darrell Neufer

Effects of Exercise on Vascular Function,

Structure, and Health in Humans

Daniel J. Green and Kurt J. Smith

Control of Muscle Metabolism by the Mediator

Complex

Leonela Amoasii, Eric N. Olson and Rhonda

Bassel-Duby

Theoretical and Biological Evaluation of the Link between Low Exercise Capacity and Disease Risk Lauren Gerard Koch and Steven L. Britton

For additional articles in this collection, see http://perspectivesinmedicine.cshlp.org/cgi/collection/ 